\title{
Estudo de correlação entre a postura e dimensões da bacia em Rhode Island $\operatorname{Red}(*)$
}

\author{
A. P. TORRES e E. A. GRANER \\ Escola Superior de Agricultura "Luiz de Queiroz" \\ Universidade de São Paulo
}

INDICE

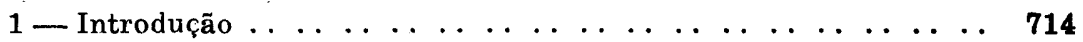

2 - Material e Método . . . . . . . . . . . . . . . . . . . . . . . 717

3-Resultados . . . . . . . . . . . . . . . . . . . . . . . . . . . .

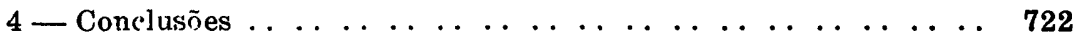

5 - Abstkact . . . . . . . . . . . . . . . . . . . . . . 724

6 - Bibliografia $\ldots \ldots \ldots \ldots$

(*) Trabalho da Seção de Avicultura e Cunicultura. 


\section{1 - INTRODUÇÃO}

Uma das operações mais importantes na prática avícola é a eliminação das aves improdutivas ou muito pouco produtivas, que cons'iituem um pêso morto na exploração, contribuindo para a reduçăo da renda líquida. Este processo não pode ser chamado de seleção, porque é baseado exclusivamente no expurgo de aves nitidamente inferiores e de rebanhos que nem sempre se destinam à reprodução. Os americanos chamam de "culling" a esta operação.

Há séculos vêm os criadores observando os caracteres externos das galinhas poedeiras na pretensão de distinguir as boas das más. Em todos os livros ou tratados de avicultura se encontra uma descrição dos caracteres de uma galinha em alta postura afim de distinguí-la daquelas de postura baixa ou paralizada. Entre êsses caracteres têm-se dado sempre grande importância ao afastamento dos ossos pelvicos, assim como a distância que separa êstes ossos da extremidade da quilha.

LAMION e KINGHORNE (1) explica-nos que devendo o ovo passar entre êsses ossos (pélvicos) por ocasião da postura, numa boa poedeira deve haver suficiente espaço entre êles, assim como devem ser moles e flexiveis afim de não retardarem oú obstruirem a passagem do ôvo. Quando a galinha está em postura, o afastamento dêsses ossos é maior do que quando não em postura. O espaçamento pode ser medido colocando-se os dedos entre êles; quando apenas dois ou menos podem penetrar é altamente provável que a galinha não esteja pondo, enquanto que se o afastamento for superior a 2 dedos é claro que a galinha está em condição de postura.

Nas galinhas em produção ativa, os orgãos abdominais e produtores de ovos aumentam a distância entre a extremidade da quilha e os ossos pélvicos. Segundo KNANDEL (2) durante a postura o ovário e o oviduto aumentam aproximadamente 7 vezes, em relação ao seu tamanho fora dessa época, de maneira que o abdome se torna cheio, mole, flexivel, enquanto na má poedeira é pequeno, contraído e duro.

No caso das raças maiores como Plymouth Rocks, o afastamento é de 4 a mais dedos entre as pontas dos ossos pélvicos e a ponta do externo ou quilha, ao passo que nas Leghorns é de 3 ou mais dedos na galinha em postura.

Há entretanto certas compensações, assim uma ave que bóte ovos pequenos, terá necessariamente medidas menores do que outra que bote ovos grandes. Uma galinha de corpo longo 
que meça 3 dedos entre os ossos pélvianos e a quilha pode ser comparada, se equivalente noutros aspectos, a outra de corpo mais curto medindo 4 dedos nesta seção.

LAMON e KINGHORNE (1) chamam também atenção para o fato das pontas dos ossos pélvicos serem mais duras e menos flexíveis, geralmente cobertos de gordura, nas aves não em postura, devido ao fato dessa condição geralmente promover a engorda do animal.

O estudo dos óssos pélvicos e da quilha se deve ao avicultor americano Walter Hogan, de Petaluma (Califórnia), que tendo dedicado toda sua vida ao estudo da conformação das boas e más poedeiras expôs conclusões num pequeno volume intitulado "The Cull of the Hen", que infelizmente não dispomos, pois numerosos autores fazem referência ao seu método de maneira suscinta e às vezes ligeiramente divergente.

Temos a impressão, pela exposição feita a respeito por DIFFLOTH (3), que o método foi apresentado como um processo a ser utilizado na seleção, afim de substituir, pelo menos parcialmente, o ninho alçapão, caro e trabalhoso. $O$ método de Hogan, segundo DIFFLOTH (3) incluia também o estudo da muda e nos Estados Unidos alcançou grande popularidade chegando a ser considerado infalível por alguns especialistas.

Na Estação Experimental de Agricultura do Texas, SHERWOOD (citado por DIFFLOTH) examinou 128 individuos da raça Langshan, tirando as seguintes conclusões a respeito do sistema de Hogan :

1) Existe uma extreita relação entre a postura e a flexibilidade dos óssos pélvianos.

2) A flexibilidade e fineza da pele são um indício de alta postura.

3) A postura está em relação com o período de muda. As más poedeiras mudam antes das boas. óvos.

4) Não existe relação entre a postura e a quantidade de

5) O pêso da galinha está em relação com a capacidade intestinal e a profundidade do corpo, assim como com o comprimento do esterno está também em relação com o arco pélviano, mas êste detalhe está longe de ser usado.

6) A postura não está em relação com o pêso; comparado êste com os caracteres anatômicos, tais como a cavidade abdominal, a profundidade do corpo, a largura da bacia e o comprimento do esterno. A prática da seleção, baseada nêstes caractéres é levada muitas vezes demasiado longe. 
7) Existe uma relação entre a côr dos tarsos e do bico com a produção: as galinhas que possuem a côr amarelo forte são as poedeiras mais mediocres. Êste estudo segundo DIFFLOTH não confirma a teoria de Hogan porém a regulariza bastante.

Em CASTELLÓ (4) encontramos a recomendação de Hogan dêste método para determinar as qualidades boas de postura em frangas de 6 a 7 meses, porém êsse mesmo autor acha que o método não é seguro para avaliar o gráu de postura de ave.

Alguns estudos foram feitos na Europa afim de verificar a correlação entre a postura e as duas dimensões da bacia. Encontramos algumas referências dêsses trabalhos em LAHAYE e MARCQ (5) sôbre os trabalhos de WEINMILLER, SWEERS da Alemanha e SCHOLTEN da Holanda.

WEINMILLER, entre outras conclusões, apresenta as seguintes, que nos interessam, estudando raças leves:

a) As galinhas tendo uma quilha relativamente longa e uma grande distância entre sua extremidade e os óssos da bacia são boas poedeiras;

b) A última distância mencionada, considerada por si só, não é uma prova de boa postura;

c) O afastamento entre os óssos da bacia deveria igualar $1 / 3$ do comprimento do corpo; as aves tendo menor afastamenmento são más poedeiras.

SWEERS não achou nenhuma correlação direta entre a postura e o afastamento dos ossos pélvicos, entre a extremidade da quilha e as extremidades dos ossos pélvicos e o comprimento, comparando essas medidas com a produção real.

SCHOLTEN estudou diversas medidas do esqueleto em aves das raças Leghorn e Barneveld, obtendo as seguintes conclusões de nosso interesse :

a) para a distância entre a extremidade da quilha e as extremidades dos óssos pélvicos a correlação com a produção de ovos foi igual a 0,286 $\pm 0,0341 \mathrm{em}$ Leghorn e 0,290 $\pm 0,0533 \mathrm{em}$ Barneveld;

b) para a distância transversal entre as extremidades dos ossos pélvicos e a produção de óvos a correlação foi de 0,298 $\pm 0,0339$ em Leghorn e 0,391 $\pm 0,0493$ em Barneveld;

c) a distância relativa entre as extremidades da quilha e dos ossos pélvicos, e entre esses dois óssos são maiores na Leghorn do que na Barneveld;

d) existe correlação positiva entre as diferentes medidas exteriores da galinha e a quantidade dé óvos que ela põe, mas 
esta correlação é tão fraca que não teria valor na seleção das aves de maior produção; é muito fraca para ter valor prático quer nas raças grandes quer nas pesadas.

Praticando o método de Hogan, do qual associavamos as medidas da bacia a outros caractéres esternos, durante alguns anos em nossa Seção de Avicultura, tornando-nos cada vez mais suspeitosos da sua exatidão, e, como nesse método davamos um valor todo especial ao afastamento dos óssos pélvicos e ao afastamento dêstes em relação à quilha, resolvemos realizar uma investigação afim de determinar em que gráu êle podia ser utilizado.

\section{2 - MATERIAL E MÉTODO}

O material utilizado nesta experiência constou de um grupo de galinhas de idade aproximada de 12 meses, da raça Rhode I. Red, relativamente uniforme e pertencente à Seção de Avicultura da Escola Superior de Agricultura "Luiz de Queiroz".

As medidas de afastamento entre as pontas dos óssos pélvicos e entre os óssos pélvicos e a ponta da quilha foram tomadas pela mesma pessôa, utilizando os dêdos como unidade, da mesma fórma como se pratica usualmente entre os criadores de galinhas. No caso presente, a largura de 1, 2, 3, e 4 dedos da pessoa que executou as mensurações foi igual a $20,40,57$ e $75 \mathrm{mms}$.

Foram tomadas as medidas de 285 frangas de primeira postura, que constitu1a um parque de reprodução coletivo e tinham contrôle individual por meio de ninho alçapão desde o início da postura, aproximadamente 6 meses.

Após a realização das medições, seus resultados foram comparados com a postura individual, tanto no último mês, contado da data da medição até 30 dias anteriores, como também do total correspondente aproximadamente 6 meses de postura do grupo em estudo.

Considerando que as duas medidas da bacia da galinha, transversal e vertical, poderiam variar independentemente favorecendo-se, compensando-se ou prejudicando-se embora tivessem elas a mesma causa original, resolvemos adotar um índice que representasse a proporcionabilidade dessas medidas comparadas a postura. Consideramos pois como índice do tamanho da bacia o produto das duas dimensões. 
De posse dos dados mencionados, fizemos o estudo da correlação entre as medidas abaixo descriminadas e a postura do último mês e nos 6 meses anteriores (total), afim de constatar si o tamanho da bacia dependia da postura total ou da postura recente. Os seguintes símbolos sẫo utilizados no decorrer do trabalho :

$l=$ largura entre as extremidades dos ossos pélvicos;

$\mathrm{h}=$ distância entre as extremidades dos óssos pélvicos e a ponta da quilha;

$\mathrm{i}$ - índice da bacia $=1 \times \mathrm{h}$.

As posturas estão representadas pelas seguintes notação: $\mathrm{p}=$ postura do último mês;

pt $=$ postura total do grupo, aproximadamente de 6 meses. fórmula :

Os coeficientes de correlação foram calculados segundo a

$$
\mathrm{r}=\frac{\Sigma_{\mathrm{xy}}-\frac{\Sigma \mathrm{x} \Sigma \mathrm{y}}{\mathrm{n}}}{(\mathrm{n}-1) \cdot \sigma \mathrm{x} \cdot \sigma \mathrm{y}}
$$

e os coeficientes de correlação parcial de acôrdo com a fórmula:

$$
\begin{gathered}
r_{a b-c}=\frac{r_{a b}-r_{a c} \times r_{b c}}{\sqrt{\left(1-r^{2}{ }_{a c}\right)\left(1-r^{2}{ }_{b c}\right)}} \\
3-\text { RESULTADOS }
\end{gathered}
$$

Para maior clareza da exposição relataremos por partes os resultados obtidos. postura.

a) Comparação da largura entre os óssos pélvicos $e$ a

A análise correlação entre o espaçamento dos óssos pélvicos e a postura do último mês $(l \times p)$ revelou o valor de $r=+0,23$ (significante no limite de $1 \%$ ) indicando uma correlação positiva entre os caractéres estudados.

A análise das mesmas medidas dos óssos pélvicos e a postura total indicou o valor de $r=+0,18$, também significante no limite de $1 \%$, mostrando ainda haver uma correlação positiva 
entre a medida dos óssos pélvicos e a postura total dos primeiros 6 meses. Comparando-se a postura do último mês com a postura total da mesma ave observou-se a correlação de $+0,55$, bastante significante.

Analisando-se a correlação parcial entre as três medidas estudadas, verificamos que, ao eliminar o efeito da postura total, o índice de correlação parcial entre a largura dos óssos pélvicos e a postura do último mês $(l \times p)$ é igual a $+0,16$, ainda significante no limite de $1 \%$, indicando uma correlação direta e positiva entre as duas medidas consideradas.

Eliminando-se agora o efeito da produção do último mês, o coeficiente de correlação parcial torna-se igual a $+0,07$, valor insignificante, mostrando que ao eliminar o efeito da postura do último mês, desaparece a correlação positiva entre a largura dos óssos pélvicos e a postura total dos 6 meses. Em outras palavras, a largura dos óssos pélvicos está mais correlacionada com a postura do último mês do que com os anteriores. A análise de correlação parcial entre as duas posturas, $r=+0,53$, confirma a correlação positiva observada entre essas duas medidas.

\begin{tabular}{c|c|c}
\hline Medidas & $\mathbf{r}$ & $\mathrm{r}$ (parcial) \\
\hline $1 \times \mathrm{p}$ & $+0,23$ & $+0,16$ \\
$1 \mathrm{xpt}$ & $+0,18$ & $+0,07$ \\
$\mathrm{p} \times \mathrm{pt}$ & $+0,55$ & $+0,53$ \\
\hline
\end{tabular}

b) Comparação da distância entre os ossos pélvicos e a quilha com a postura.

A distância que vai dos ossos pélvicos à quilha e a postura do último mês não se mostraram correlacionadas. $O$ valor de $r$ é igual $a+0,11$, valor êste insignificante. $O$ meșmo já não acontece com essa medida comparada à produção total dos últimos 6 meses. A análise de correlação para êste último caso mostra o valor de $r$ igual a $+0,21$, significante do limite de $1 \%$. As anảlises das correlações parciais confirmam a falta de correlação entre a medida considerada e a produção do último mês, eliminando-se o efeito da produção total, e a existência de uma 
correlação positiva entre essa medida e a postura total dos últimos 6 meses eliminando o efeito da produção do último mês. Os valores de $r$ são respectivamente $-0,01 \mathrm{e}+0,18$. A correlação entre a postura do último mês e a postura total dos ultimos 6 meses, eliminando o efeito da distância entre os óssos pélvicos e a quilha, permanece constante.

\begin{tabular}{c|c|c}
\hline Medidas & $\mathbf{r}$ & $\mathrm{r}$ (parcial) \\
\hline $\mathrm{h} \times \mathrm{p}$ & $+0,11$ & $-0,01$ \\
$\mathrm{~h} \times \mathrm{pt}$ & $+0,21$ & $+0,18$ \\
$\mathrm{p} \times \mathrm{pt}$ & $+0,55$ & $+0,54$ \\
\hline
\end{tabular}

c) Comparação do índice $l \times h$ e a postura.

Foram também analisadas as correlações entre os índices obtidos do produto da medida de largura dos ossos pélvicos pela distância dos mesmos à quilha com a postura.

$\mathrm{O}$ valor de $r$ obtido para o índice e a postura do último mês foi igual a $+0,27$, significante no limite de $1 \%$, pouco diferindo do valor $+0,23$, obtido quando da análise entre largura dos ossos pélvicos e a mesma postura. No caso do índice e produção total dos últimos 6 meses, o valor de $r$ foi igual a $+0,18$, também significante no limite de $1 \%$, indicando ainda a correlação positiva entre esses dois valores.

A análise de correlação parcial entre o índice e a produção do último mês, eliminando o efeito da produção total, confirma correlação positiva observada entre os dois valores considerados. $O$ valor de $r$ no caso da correlação parcial entre o índice e a produção total, eliminado o efeito da produção do último mês, é igual a $+0,04$, valor insignificante.

Estas análises mostram que o comportamento do índice é pràticamente o mesmo daquele obtido com a medida largura entre os ossos pélvicos e a postura. Fazendo-se constante o índice, a correlação parcial entre a postura do último mês e a postura total permanece pràticamente a mesma com o valor de $r$ igual a $+0,53$. 


\begin{tabular}{c|c|c}
\hline Medidas & $\mathrm{r}$ & $\mathrm{r}$ (parcial) \\
\hline $\mathrm{i} \times \mathrm{p}$ & $+0,27$ & $+0,19$ \\
$\mathrm{i} \times \mathrm{pt}$ & $+0,18$ & $+0,04$ \\
$\mathrm{p} \times \mathrm{pt}$ & $+0,55$ & $+0,53$ \\
\hline
\end{tabular}

d) Gráfico das análises

As análises de correlação para o caso do índice e postura estão ilustradas nos gráficos I e II.

\section{GRÁFICO I}

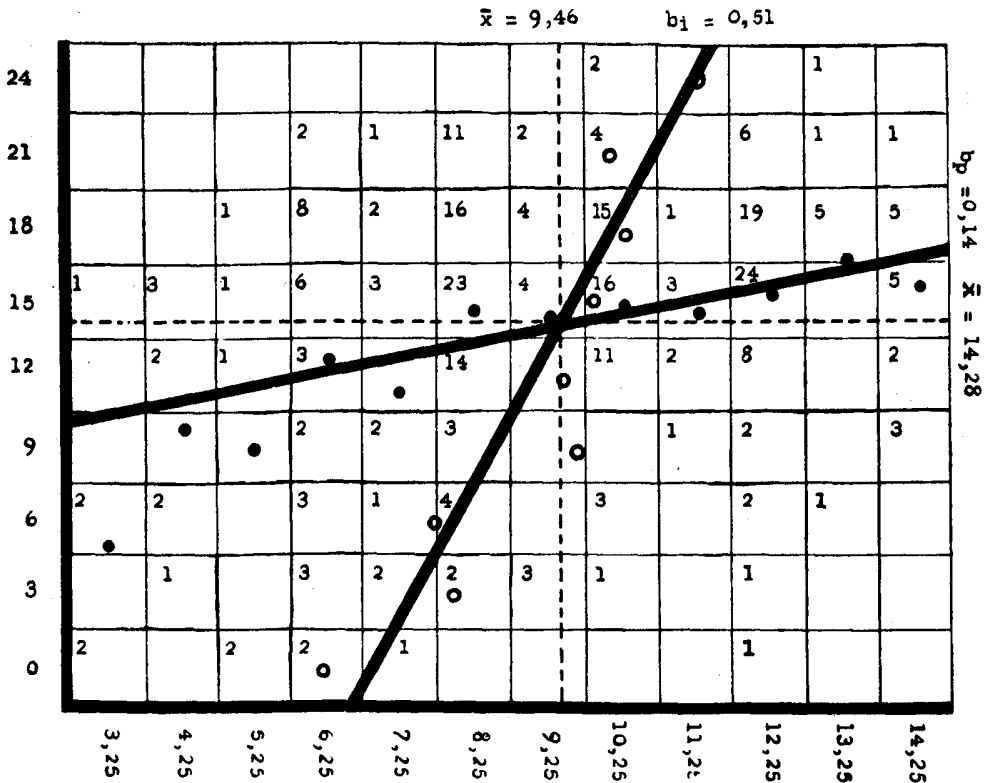

O gráfico I representa a correlação entre o índice e a produção do último mês, estando representados na abcissa os indices e na ordenada as produções do último mês. 


\section{GRAFICO II}

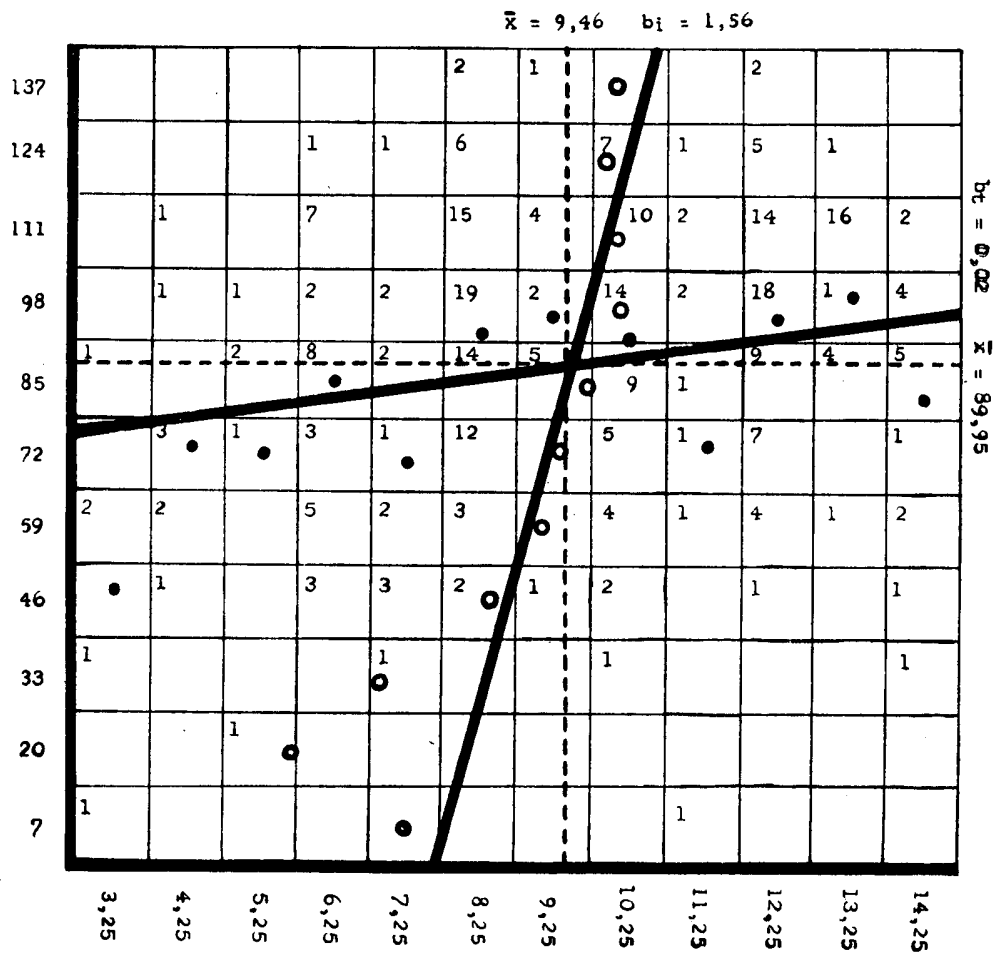

O gráfico II contém os dados da análise entre o índice e a produção total, estando representados na abcissa os indices e na ordenada as produções totais dos últimos 6 meses.

O gráfico III representa a análise de correlação realizada entre a produção do último mês e a produção dos últimos 6 meses. $\mathrm{Na}$ abcissa estão representados as produções parciais e na ordenada as produções totais.

\section{4 - CONCLUSÕES}

Do estudo realizado com 285 frangas Rhode I. Reds, nos seus primeiros 6 meses de postura os AA. constataram que :

1) Houve correlação positiva entre a largura dos ossos pélvicos e a produção do último mês. Esta correlação coincide com 
os resultados de outros autores, não sendo suficientemente alta para uma aplicação segura.

\section{GRAFICO III}

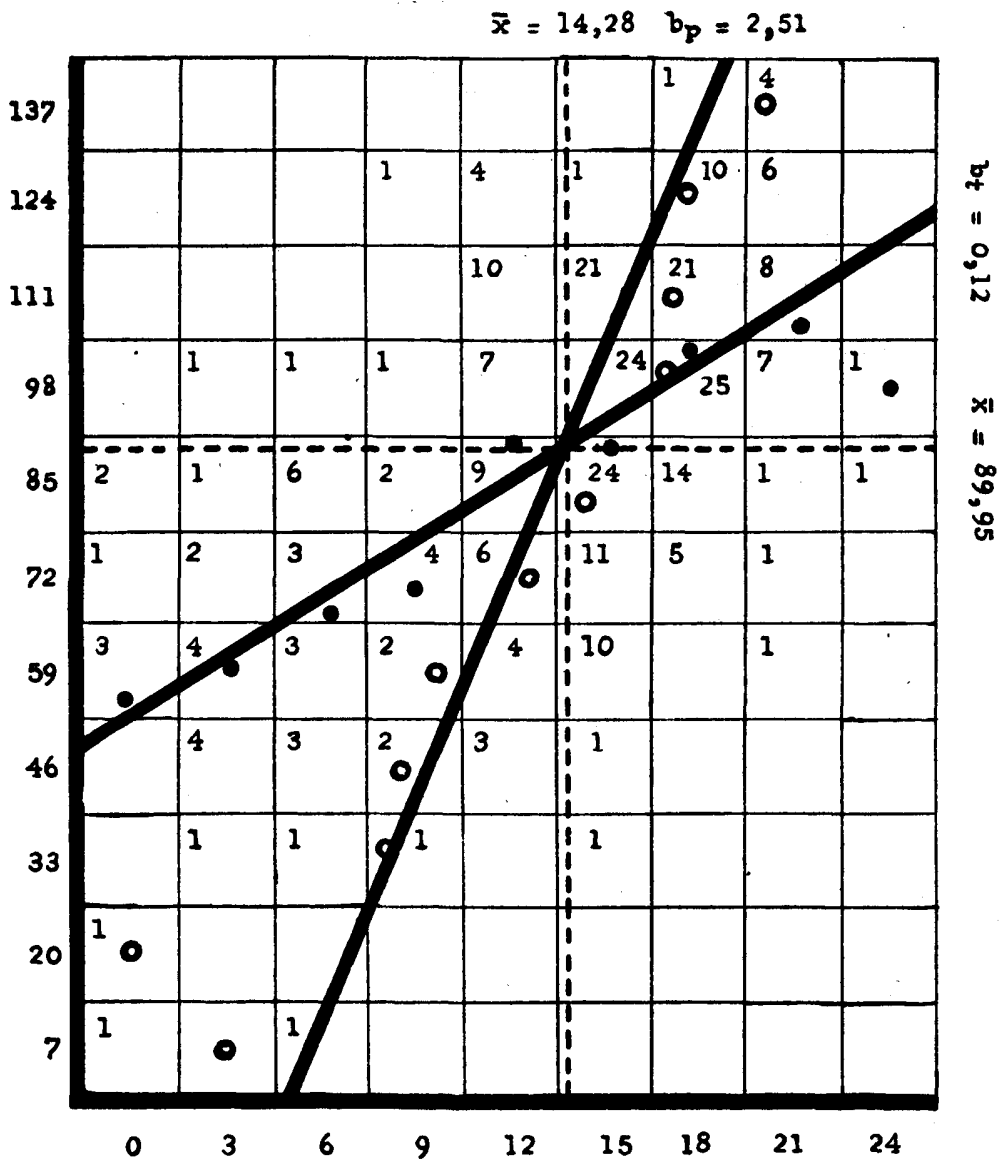

2) Não houve correlação entre a distância dos óssos pélvicos e a ponta da quilha em relação à produção do último mês, o que mostra que essa medida é pouco útil para avaliar a produção atual.

3) Houve correlação positiva entre a distância dos óssos pélvicos à ponta da quilha e a produção total dos últimos 6 me- 
ses, embora esta correlação não seja suficientemente alta para dar ao avicultor maior segurança no seu emprêgo.

4) A análise do índice $l \times h$, sugerido pelos AA., revelou os mesmos resultados da análise do espaçamento dos óssos pélvicos, demonstrando não haver vantagem no seu emprêgo, que constitue uma inutil complicação.

Finalmente, conclui-se que a medida transversal da bacia tem emprêgo limitado para determinar a intensidade da postura no momento do exame. Si o espaçamento entre os óssos pélvicos fôr demasiado reduzido, de 1 dedo, é seguro afirmarse que a ave não está pondo. Si o espaçamento é muito largo e os óssos muito-flexíveis, é seguro afirmar-se que a ave está pondo. Os casos intermediários, que constituem a maioria não apresentam entretanto a mesma segurança. Aliando-se contudo o método ao exame de outros caractéres êle possue ainda alguma utilidade.

Em relação a espaçamento entre os ossos pélvicos e a ponta da quilha constatou-se depender mais de um grande desenvolvimento do abdome provocado por uma postura prolongada, do que influenciado por uma postura recente.

\section{5 - ABSTRACT}

The AA. have studied, in this paper, the correlation of egg production in yearling R. I. R. pullets and the difference between the pelvic bones, an between the pelvic bones and keel.

The distances between those bones were measured by the fingers. It was suggested an index $=$ spread of pelvic $\mathrm{x}$ spread of keel bone. These three data were compared with the last 30 days production and with the production to date - six months. Comparisons have been made with 285 pullets.

The AA. have concluded:

(a) there is a positive correlation between the spread of the pelvic bones and the last 30 days $(r=+0,23$ and $\mathrm{pr}=+$ $0,16)$;

(b) there is not correlation of the distance between the pelvic bones to the keel and the last 30 days $(r=+0,11$ and $\mathrm{pr}=-0,01$

(c) there is positive correlation of the distance between the pelvic bones to the keel and last six months production $(\mathrm{r}=+0,27$ and $\mathrm{pr}=+0,19)$;

(d) the correlation of the index sugested pratically equals correlation between pelvic bones $(r=+0,27$ and $\mathrm{pr}=+0,19)$; 
(e) correlation between last 30 days production and the total egg production is high $(\mathrm{r}=+0,55$ and $\mathrm{pr}=0,53)$.

Is is stated that spread of the pelvic bones is a low index of actual production and the distance of the keel a low index of total egg production in R. I. R. pullets. The last month real production is a better index of the total egg production.

\section{6 - BIBLIOGRAFIA}

1 - LAMON, H. M. and KINGHORNE, J. W., 1931 - How to eslect the laying Hen, Orange Judd. New York.

2-KNANDEL, H. C., 1943 - Profitable Poultry Keeping, Orange Judd. New York.

3-DIFFLOTH, P., 1929 - Metodos Modernos de Avicultura. 1a. Ed. Esp., Salvat Ed. Barcelona.

4-CASTELLO, S., 1934 - Tratado Proctico de Avicultura, Imp. Nac. Bogota.

5-LAHAYE, J. et MARCQ, J., 1933 - Traité complet d'Aviculture, Enc. Agr. \& Vet. Gembloux, Paris.

6-GRANER, E. A., 1951 - Como aprender Estatística. Com. Melhoramentos, S. Paulo (em impressão). 
